\title{
As representações do papel do professor de português
}

\section{The representations of the Portuguese teacher's role}

Rute Izabel Simões Conceição*

Universidade Federal da Grande Dourados

RESUMO: Nosso objetivo é demonstrar os resultados de uma investigação sobre as representaçōes do papel do professor de Língua Portuguesa construídas por acadêmicos concluintes de cursos de Letras. Foram discutidos os possíveis reflexos dessas representações no modo como a língua tem sido ensinada e socialmente representada no país. O recorte teórico da pesquisa sustentou-se numa abordagem sócio-histórica e ideológica da linguagem, conforme asseveram Bakhtin/Volochínov (1995) e Bakhtin (2003). A análise dos dados apoiou-se no paradigma indiciário (GINZBURG, 1998), para realizar o rastreamento e a interpretação dos indícios das representações. Os resultados apontam para dois tipos predominantes de representaçôes do papel do professor - o do professor-repassador de conteúdos e o do professor-repassador de conteúdos com alçamento a professor-investigador. PALAVRAS-CHAVE: Professor de língua portuguesa; estudo e ensino de língua portuguesa; representações sociais da língua.

ABSTRACT: Our aim is to demonstrate the results of an investigation about the representations of the Portuguese language professor's role which are built by the undergraduate students of a Language Course in their last university year. The possible outcomes of these representations were discussed based on how this language has been taught and socially represented in the country. The theoretical cut of this research was nurtered by a social, historical and ideological approach of language, according to Bakhtin/Volochínov (1995) and Bakhtin (2003). The data analysis was supported by the study of signs (GINZBURG, 1998), to start the tracking and the interpretation of those representations and their clues. The results point to two predominant types of representations of the content-repassing teacher and of the content-repassing teacher with projection to an investigativeteacher.

KEYWORDS: Portuguese language teacher; teaching and learning Portuguese; social representations of language.

*ruteconceicao@ufgd.edu.br 


\section{Introdução}

O processo de globalização mundial caminha a passos largos em direção à homogeneização econômica, social e cultural, fato amplamente discutido em diferentes segmentos da sociedade e denunciado com veemência nas Declaraçóes da UNESCO, em especial na última Declaração dirigida ao setor educacional e elaborada em 1998, em Paris - a "Declaração Mundial sobre Educação Superior no século XXI: visão e ação". Essa Declaração, vale dizer, é um alerta para que as instituições de ensino superior, além de buscarem a excelência no seu desempenho, tomem a iniciativa de criar estratégias de preservação da diversidade, da autonomia e da identidade cultural dos países. Uma das formas de criar tais estratégias é por meio da avaliação da qualidade do ensino, em especial de nível superior, iniciativa que, no Brasil, vem se efetivando, por exemplo, por meio do Exame Nacional de Desempenho do Estudante (ENADE), iniciativa sobre a qual este trabalho tem particular interesse.

Alinhando-se, também, ao franco desenvolvimento que tem ocorrido no campo dos estudos do letramento, mais especificamente dos estudos das representações sociais da escrita, nosso trabalho procurou realizar a descrição e a análise dos modos de representação do papel do professor de Língua Portuguesa construídos por formandos em Letras do estado xxx, em textos produzidos durante o Exame Nacional de Cursos, realizado em 2001, pelo Ministério da Educação. ${ }^{1}$

Pretendemos contribuir para uma melhor compreensão de alguns princípios contidos nas políticas públicas voltadas para a educação brasileira (tais como a dos Parâmetros Curriculares Nacionais e a das avaliações dos estudantes e das Instituiçóes de Ensino Superior brasileiras, por exemplo) e fornecer elementos para uma reflexão sobre a formação do professor de língua materna no país.

Levando em consideração todo esse contexto, organizamos esta apresentação expondo primeiramente os aportes teóricos que dão sustentação à investigação, cujo recorte estabelecido procurou relacionar as discussōes sobre letramento, sobre gêneros do discurso e sobre as relações entre fala e escrita com questôes ligadas ao ensino da língua portuguesa no Brasil. Na sequência, descrevemos a metodologia que orientou a análise dos dados, seguida dos resultados da pesquisa.

\footnotetext{
${ }^{1}$ A autorização para uso do material foi concedida pelo INEP-MEC, conforme ofício INEP/DAES no. 001708/2002 de 02/04/2002. Dados do autor.
} 


\section{Considerações teóricas}

No campo dos estudos do letramento e das representaçōes sociais da escrita, têm se desenvolvido pesquisas que mostram que fala e escrita são práticas sociais que se inter-relacionam (CORRÊA, 2004; MARCUSCHI, 1998; CONCEIÇÃO, 2008). Contudo, se no campo científico os avanços nas pesquisas merecem destaque e comemoração, no campo do ensino, $o$ avanço ainda é muito pequeno. Neste campo, as práticas de ensinoaprendizagem de língua portuguesa em sala de aula, que sempre privilegiaram o ensino da escrita numa perspectiva bastante tradicional, em detrimento do ensino voltado para o letramento efetivo de alunos falantes de variedades linguísticas desprestigiadas, não têm sofrido grandes alteraçōes. Quando utilizamos a expressão "prática de ensino da escrita numa visão bastante tradicional", estamos afirmando que consideramos tradicional o fato de ainda se conceber o ensino da norma-padrão como o único modelo de língua a ser ensinado nas aulas de língua materna na escola, em vez de considerá-la uma das variedades linguísticas implicadas nos diversos gêneros com suas diferentes formas composicionais que a escola deve levar os alunos a tomarem contato ao longo da escolarização. Tal posição não significa, no entanto, que a escola esteja desincumbida de levar os alunos falantes de variedades desprestigiadas a dominarem as formas de prestígio, por exemplo, aquela presente na literatura chamada clássica. O que defendemos é que a escola deve assumir o compromisso de promover o letramento dos alunos por meio de uma prática intensa de leitura, de escrita e de oralização de diversos gêneros, e não só por meio do exercício descontextualizado (ou contextualizado) de fixação de uma única norma.

A questão do ensino de língua centrado nos gêneros tem sido muito discutida ultimamente e o nome de referência na questão teórica sobre gêneros do discurso é o de Bakhtin (2003). Ele postulou que toda a comunicação humana se dá nas formas dos gêneros e, em toda produção, há um cruzamento de diferentes vozes no enunciado, de forma que este sempre estará marcado pelas histórias dos seus acontecimentos. É a partir desse teórico que a questão das relações intergenéricas passou a ser estudada.

Corrêa (2006), sustentando-se em Bakhtin, defende que as relações intergenéricas são constitutivas de qualquer gênero. Conceber a questão dos gêneros nessa perspectiva significa ultrapassar atitudes ingênuas que buscam mecânica e unicamente no espaço de sala de aula ou, no contexto familiar, explicações para os fatos textuais-discursivos das produçōes escritas dos alunos, 
assevera o autor. Afirma ainda que, nessa perspectiva, as partes mais ou menos informes de outros gêneros discursivos, quando presentes em um determinado gênero, ganham estatuto de fontes históricas da constituição de uma fala ou de uma escrita, em vez de serem vistas como erros ou falhas cometidas na elaboração discursiva (CORRÊA, 2006, p. 209).

Tal visão ainda está distante da prática linguística e da norma pedagógica ensinada na escola brasileira. A norma-padrão que temos hoje descrita nas gramáticas normativas tradicionais (são elas que têm dado sustentação à norma pedagógica ensinada em sala de aula no Brasil), foi estabelecida com base em uma prática linguística bem distante do falar e do escrever da grande maioria dos brasileiros e da visão de um ensino centrado nos gêneros do discurso e nas relaçóes intergenéricas. Na verdade, a grande maioria dos brasileiros, desde $\mathrm{o}$ período colonial até o final do século XX foi mantida analfabeta e, portanto, sem o direito de ter sua voz ouvida por meio da escrita ou mesmo da fala. É preciso ressalvar, no entanto, que a própria Linguística e a Sociolinguística, entre outras ciências que se interessam pelas variedades linguísticas efetivamente utilizadas nas interações sociais, são bastante recentes, de maneira que tais discussões, tanto no estudo como no ensino da língua, há bem pouco tempo, não faziam sentido. Somente nas últimas décadas, as práticas linguísticas menos prestigiadas (isto é, aquelas que mais se distanciam do modelo estabelecido como padrão) passaram a ser estudas. Antes disso, a escrita (cujo modelo de referência era a escrita literária) ocupava praticamente todos os espaços reservados à pesquisa e ao ensino da língua.

Não se pode negar que a tecnologia da escrita certamente deu grande contribuição para o desenvolvimento da humanidade, no entanto, a escrita passou a ser tão supervalorizada ao longo dos anos que levou a fala a ser deixada em segundo plano e, em muitos casos, equivocadamente, a ser considerada um bem menor. No Brasil, país em que a língua escrita e o acesso à variedade padrão é privilégio de poucos, são, no mínimo, curiosas certas representações construídas em torno da língua escrita.

Em nosso país, a língua escrita em sua variedade chamada padrão, historicamente, tem sido tratada como a única portadora de autoridade capaz de assegurar o sentimento de comunhão e de unidade de nossa sociedade (CONCEIÇÃO, 2008b). Esse sentimento tem estreita relação com o fato de que o "princípio da idéia nacional" (HOBSBAWM, 1990) articula a moderna concepção de nacionalidade com a questão linguística e com o fato de que aquilo que tem valor simbólico de poder atrair e unir em torno de si pessoas e coisas pode tornar-se um semióforo (POMIAN, 1984). 
Nesse sentido, a língua portuguesa tornou-se um semióforo, visto que é assumida como um símbolo de coesão nacional no país. Segundo Conceição (2008a; 2008b), a principal característica de uma língua semióforo é a de se revestir de poder simbólico capaz de assegurar a interação e o sentimento de comunhão e, assim, representar a unidade da nação.

Uma língua semióforo comporta duas faces (uma tida como homogênea e outra heterogênea) organicamente ligadas: a face tida como homogênea é aquela que foi codificada e tornada padrão oficial do país, passou a figurar nos documentos e seu domínio passou a ser requerido na escola. Ela dá status e tem a função de conter a diversidade linguística; a outra face, a heterogênea, dá-lhe vida e é revelada por meio do uso cotidiano. A face heterogênea se mostra acolhedora de diferentes variedades. Historicamente, no entanto, esta face da língua tem sido tratada com sentimento de inferioridade.

Para orientar a reflexão sobre tais questôes, buscamos fundamentação no conceito de representação social nas proposiçōes de Cornelius Castoriadis (1982-1975). A perspectiva proposta pelo estudioso é inversa à proposta pela tradição, já que esta dicotomiza o histórico e o social e entende que o conjunto da vida social e as instituições correspondem a um sistema funcional em que existe uma série de arranjos destinados à satisfação das necessidades da sociedade. Para Castoriadis, essa concepção leva a crer que o conjunto de necessidades humanas são fixas, de maneira que seria possível explicar a organização social como o "conjunto das funçōes que visam satisfazê-las" (CASTORIADIS, 1982, p.140).

Embora não negue que as instituições se formam para serem funcionais, visto que devem assegurar a sobrevivência da sociedade, afirma que é impossível dizer que tudo na sociedade seja funcional ou que as instituições se limitem a isso. Assumindo, portanto, posição sócio-histórica e diversa à instaurada, por exemplo, pela perspectiva funcionalista de estudo das representaçōes, o filósofo afirma que, para refletir sobre as representaçôes sociais é necessário levar em conta o modo como se constrói o conceito de tempo sócio-histórico. E afirma que a construção do tempo ${ }^{2}$ sócio-histórico se dá em duas dimensôes: a identitária

\footnotetext{
${ }^{2}$ Émile Benveniste (1985-1966, p. 68-80) destaca a existência de três níveis de tempo: o tempo físico (segmentável à vontade); o crônico (dos acontecimentos) e o linguístico (inserção de um acontecimento no tempo da língua). Este último está ligado aos dois primeiros, mas é definido e organizado em função do discurso, pelo exercício da enunciação.
} 
e a imaginária. O tempo identitário corresponde ao tempo cronológico, ao tempo mensurável e o tempo imaginário é tempo da significação ou significativo (CASTORIADIS, 1982, p. 247). Embora diferentes, estão intimamente ligados, de maneira que um tempo dá sentido para o outro.

Nessa perspectiva, a sociedade instituída precisa conter o real, que é instituído por e para cada sociedade, e jamais será totalmente arbitrário; e precisa conter também o racional, que representa o real-simbólico ou o que é indispensável para pensá-lo. Em outros termos, ao entender as representações desse modo, pressupõe-se que a sociedade não constitui seu simbolismo numa liberdade total, visto que alguns aspectos da vida em sociedade podem ser previstos; outros, não.

Em cada sociedade, o que ocorre é uma manifestação ativa dos momentos privilegiados da atividade social (referentes à cultura, à economia, à política, entre outros) e uma manifestação da instituição da ordem do mundo, tal qual é instituída pela sociedade. É, portanto, constituindo o tempo sócio-histórico dessa forma que Castoriadis propõe sua concepção de representação social e de sociedade, considerando que esta é sempre histórica, visto que "o presente é sempre constituído por um passado que o habita e um futuro que o antecipa, isto é, o presente é sempre um presente histórico (CASTORIADIS, 1991).

É levando em conta todo esse contexto que, neste trabalho, assumimos que as representações construídas pelos futuros professores sobre o papel do professor de língua materna, ao longo do seu processo de letramento, devem ser levadas em consideração nos cursos de formação de professores. Assim, admitimos que a explicitação das representações do papel do professor de língua materna pode contribuir para fornecer elementos para propostas de intervenção crítica no ensino superior, em especial na formação do professor de Língua Portuguesa, de modo a fortalecer e a orientar o processo de revisão e de elaboração de propostas didáticas para o ensino de língua materna que vem se desencadeando nos últimos anos no país.

Nesse quadro que se delineia, a avaliação é, sem dúvida, um instrumento importante para o monitoramento, a aferição e o estabelecimento de parâmetros de qualidade da educação em todos os níveis. Nos anos 90, a política nacional de avaliação das instituições de ensino intensificou-se. Os cursos de Letras, por exemplo, passaram a ser avaliados pelo Ministério da Educação, a partir de 1998, por meio do Exame Nacional de Cursos. Em 2001 foi realizado o Exame Nacional de Cursos cujas respostas de acadêmicos de Cursos de Letras do estado xxx deram origem aos textos analisados nesta pesquisa. 


\section{A constituição do corpus e a metodologia da pesquisa}

Conforme já mencionamos, originados em 2001, durante o Exame Nacional de Cursos, os 75 textos analisados nesta pesquisa correspondem a respostas de acadêmicos de Cursos de Letras do estado xxx a uma questão discursiva que avaliava os conhecimentos de Linguística e de Língua Portuguesa.

A solicitação presente na questão do Exame propunha que os formandos apresentassem três soluçôes para os problemas de coesão de um texto-base (texto de uma criança das séries iniciais de escolarização) e justificassem as soluções apresentadas com apoio em noçôes linguísticas, conforme se pode verificar no seguinte trecho retirado da questão:

$[\ldots]$

Uma característica desse texto é a forma como a menina faz as ligaçōes coesivas. Elabore um texto no qual você proponha alteraçóes para o segundo parágrafo, apresentando três soluçōes para o problema dos elos coesivos. Justifique as alteraçôes sugeridas com apoio de noçôes lingüísticas.

Verifiquemos que a instituição avaliadora (Ministério da Educação do Brasil - MEC), ao solicitar que fossem apresentadas três soluçōes para os problemas de coesão do texto-base e que fossem apresentadas as justificativas com apoio em noçôes linguísticas, pretendia avaliar a reflexão que o formando faria a respeito da ação sobre a linguagem realizada pela criança, tal qual apontam os PCN (1998) que, lançados para dar um novo direcionamento para o ensino de língua no país, procuram tratar dos conteúdos e da metodologia do ensino de língua em sala de aula, enfocando o uso da língua e a reflexão sobre seu uso. Em outros termos, o MEC objetivava avaliar no exame, que propôs:

a) os conhecimentos de Linguística e de língua portuguesa dos formandos por meio da habilidade de interpretar textos escritos por crianças num determinado gênero;

b) os registros linguísticos utilizados, e

c) a explicitação dos processos ou argumentos utilizados para justificar tal interpretação.

Vemos, implícito nesses requisitos, a intenção de verificar, sobretudo, a capacidade que os formandos teriam de analisar o uso da linguagem feito por 
crianças em idade escolar que, supostamente, serão seus alunos, quando formados. Considerando tal perspectiva, assumimos que a demonstração de reflexão fundamentada em aspectos linguísticos nas respostas seria reveladora do alçamento do formando à posição de professor, de modo que os resultados da investigação revelariam indícios da tendência de representação predominantemente indiciada nos diferentes tipos de respostas em todo o corpus. Procuraremos dar uma interpretação teórico-metodológica para os indícios depreendidos segundo a perspectiva proposta por Ginzburg (2003) no chamado paradigma indiciário e na perspectiva linguística proposta por Corrêa (2006), que associa a determinação de índices com fragmentos textuais singularmente marcados como réplicas.

Do ponto de vista quantitativo, considerando o universo de 75 textos analisados e o fato de que havia a expectativa de que em cada resposta fossem apresentados 3 problemas de coesão; 3 soluções e as devidas justificativas, esperava-se que houvesse a descrição de 225 casos de identificação de problemas de coesão $(75 \times 3), 225$ propostas de solução $(75 \times 3)$ e 225 justificativas com apoio em noções linguísticas ( $75 \times 3)$, perfazendo um total geral de 675 casos esperados.

Mobilizados ainda pela questão proposta no Exame, os sujeitos desta pesquisa, na condição de futuros professores de Língua Portuguesa, foram impelidos a assumir, como uma das representaçóes sobre si mesmos, o papel de professor conhecedor das teorias linguísticas, da metalinguagem técnica e dos procedimentos didáticos no ensino de língua portuguesa.

Assim, dois lugares foram estabelecidos por nós como constitutivos da representação do papel do professor de Língua Portuguesa:

a) o lugar do professor conhecedor das teorias linguísticas; e

b) e o lugar do professor conhecedor da didática do ensino da língua.

Supõe-se que esses dois lugares permitem verificar o modo como os formandos representam seu papel de professor em sua relação com o conhecimento científico da língua e seu papel de professor em relação à atuação didático-pedagógica.

A questão que nos pusemos foi a seguinte: quais indícios de posicionamento os sujeitos (futuros professores) revelam em relação à língua semióforo nos textos que escreveram em resposta à questão proposta no Exame Nacional de Cursos?

Para investigar tais posicionamentos, procuramos identificar e analisar se houve: 
a) indícios de tendência a reforçar o caráter simbólico da língua semióforo unicamente em sua dimensão homogeneizadora das diferenças linguísticas, com vistas a defender a unidade da língua padrão; e / ou

b) indícios de tendência a realizar uma reflexão sobre o caráter simbólico da língua semióforo nas duas dimensōes: na homogênea e na heterogênea, com vistas a buscar a compreensão do funcionamento do simbólico nas práticas cotidianas.

Vale dizer que não se trata de propor uma oposição que sirva para eliminar de consideração qualquer dos lados, mas de descobrir e de descrever os posicionamentos apresentados, tanto em relação à face heterogênea quanto em relação à face homogênea. Há que se ressalvar, no entanto, que, no Brasil, a face heterogênea da língua é, historicamente, vista sem os argumentos de autoridade com que a homogeneidade tem sido tradicionalmente tratada, isto é, como a única participante do sentimento de comunhão social.

\section{Os resultados da pesquisa}

No que diz respeito ao aspecto quantitativo, o levantamento geral dos dados mostrou que das 625 ocorrências esperadas, houve, ao todo, 78 ocorrências de descrição, assim distribuídas:

35 casos de problemas de coesão identificados ou $5,1 \%$ do total de ocorrências esperadas;

> 39 casos de propostas de solução descritas ou 5,7 \% do total de ocorrências esperadas;

$>4$ casos de justificativas ou menos de 1,0 \% do total de ocorrências esperadas.

Nas 35 descrições de problemas que foram apresentadas, o problema de coesão descrito com maior frequência foi a repetiçãao, correspondendo a 77\% dos problemas identificados. A proposta de solução mais apresentada, dentre os 39 casos descritos, foi a eliminação da repetição, o que corresponde a 69\% das propostas que visavam solucionar os problemas de coesão detectados. Dentre as 4 justificativas apresentadas, $0,5 \%$ do total de ocorrências esperadas, 3 fundamentaram-se na gramática normativa e uma na perspectiva linguística. Tal reação dos futuros professores evidencia que se esquivaram de apresentar a reflexão linguística conforme solicitada no Exame. 
Mesmo que não tenham atendido às expectativas institucionais, concernentes à descrição dos fatos linguísticos, considerando os diferentes tipos de respostas dados à questão do Exame pelos formandos e amparada nos fatos linguístico-discursivos apresentados, descrevemos as diferentes representaçôes que os formandos fazem do papel do professor de língua portuguesa ao assumirem, diante da língua semióforo, a posição que assumiram.

A análise, a partir desse ponto de vista, permitiu que classificássemos os 75 enunciados-resposta em dois grupos com 5 tipos de resposta. No Grupo 1, classificamos dois tipos (Tipo 1 e Tipo 2) e, no Grupo 2, classificamos três tipos de respostas (Tipo 3, Tipo 4 e Tipo 5), a seguir especificados.

Grupo 1: aqueles que centraram a resposta na análise argumentativa do texto-base:

Tipo 1 - Relato argumentativo por meio do qual os formandos procuraram demonstrar a identificação dos problemas de coesão do texto-base (texto da criança que foi proposto para os formandos analisarem no Exame), as propostas de solução e as justificativas.

\section{E5}

Na primeira oração, o pronome "eles" é usado repetidamente, quando poderia ser eliminado, pois o verbo já mostra a pessoa em que está conjugado. O pronome "que" e o advérbio "quando" também aparecem sem necessidade, assim como o substantivo "bezerros", que já havia sido mencionado anteriormente e poderia ter sido substituído pelo pronome oblíquo "os".

$\mathrm{Na}$ segunda oração o pronome "eles" poderia ser evitado, pois sua colocação na oração tornou-a incoerente, sem sentido.

Na última oração o pronome relativo "que" e o verbo "ser" no pretérito, poderiam ser substituídos por uma vírgula.

Dessa forma o texto ficaria mais coeso e objetivo.

Tipo 2 - Relato argumentativo por meio do qual os formandos demonstraram uma análise generalizada, isto é, sem a demonstração de que os problemas de coesão tivessem sido identificados.

\section{E32}

O texto escrito por esta garota de dez anos apresentado neste fragmento adaptado de "Anáfora Indireta: O Barco Textual e suas Âncoras" necessita de uma revisão no que se diz respeito a organização de idéias, clareza, argumentação... entre outros ítens. 
Sendo assim, é de suma importância que se debata qualquer assunto para depois fazer o uso da escrita, pois são as diferentes opinióes que propiciam a argumentação textual.

A organização de idéias e a clareza estão relacionadas. Para que se entenda a mensagem que o autor quer passar necessita-se de questionamentos que leve o individuo a refletir qual o seu objetivo com o que esta escrevendo.

E logicamente, a pontuação é essencial para que qualquer produção seja entendida.

Todos esses aspectos são possíveis de se trabalhar com a "Reestruturação textual”.

Grupo 2: aqueles que sustentaram a resposta na reformulação do texto-base:

Tipo 3 - Relato misto no qual os formandos apresentaram a reformulação da narrativa, seguida de análise argumentativa, por meio da qual procuraram demonstrar a identificação de algum problema e apresentar alguma proposta de solução.

\section{E33}

O passeio na ilha.

Uma família foi passar as férias em uma ilha, enfrentaram vários obstáculos no caminho, mas conseguiu chegar lá.

Já era noite, se acomodaram, e, ao dormir perceberam que os bezerros começaram a correr. Foram verificar o que era, e logo viram que era apenas um caranguejo. A esposa desesperada começou a chorar, dizendo que queria ir embora.

Mas, ao amanhecer resolveram passar mais uns dias e foram muito felizes nesse passeio.

Foi tirado o pronome pessoal "eles" que estava repetitivo, e foi colocado algumas conjunções para organizar os períodos.

Tipo 4 - Relato misto no qual os formandos apresentaram a reformulação da narrativa do texto-base seguida de análise argumentativa generalizada, sem a demonstração de que tivessem identificado os problemas de coesão do texto-base.

\section{E12}

$1^{a}$ - Ao anoitecer quando foram dormir, perceberam que alguns bezerros começaram a correr, foram ver o que era e se depararam com uma enorme sucuri engolindo um bezerro. 
$2^{\mathrm{a}}$ - Como não puderam explorar o outro lado da ilha ficaram perto do lago pescando e andando de barco no lago.

$3^{a}$ - Ao anoitecer quando foram dormir perceberam que os cavalos estavam assustados, ao verificar o que estava acontecendo se depararam com uma onça.

Pode-se com criatividade dar continuidade \# a um texto já parcialmente construido.

Tipo 5 - Relato em que os formandos apresentaram somente a reformulação da narrativa do texto-base, sem demonstrar, por meio da análise argumentativa, que tivessem identificado o problema de coesão da narrativa analisada.

E3

Anoiteceu e eles perceberam uma grande movimentação na ilha, era um enorme caranguejo que se aproximava atemorizando a todos. Débora a esposa desesperou-se.

Amanhecendo o dia a família resolveu desbravar o lugar, achando assim, o caminho de volta chegando no local, perceberam que o barco estava demolido e ao seu lado marcas de caranguejo.

A maior parte $(73 \%)$ das estratégias de resposta se sustentou na reformulação do texto-base em vez de se sustentar na descrição dos problemas linguísticos de forma argumentativa, conforme solicitado.

Tais constataçóes nos levaram às seguintes reflexóes. Os dois lugares estabelecidos como constitutivos da representação do papel do professor de Língua Portuguesa - o lugar do professor conhecedor das teorias linguísticas e o lugar do professor conhecedor da didática do ensino da língua-, permitiram depreender o modo como os formandos representam seu papel de professor em sua relação com o conhecimento científico da língua e seu papel de professor em relação à atuação didático-pedagógica. Em outros termos, as diferentes representações foram marcadas por diferentes posições diante da língua tomada como objeto de estudo e diante da língua tomada como objeto de estudo / ensino.

Nesse sentido, três modos de representação se revelaram predominantes, os quais chamamos de professor-investigador, professor-repassador de conteúdos e professor-repassador de conteúdos com alçamento a professorinvestigador. Esclarecemos que: 
professor-repassador de conteúdos seria aquele que se define pela relação passiva com a língua, não se mostra conhecedor da produção do conhecimento, nem capaz de articular os eixos epistemológicos e didático-pedagógicos;

professor-investigador seria aquele que se define pela relação ativa com a língua e com a produção do conhecimento e seu ensino; e

professor-repassador de conteúdos com alçamento a professorinvestigador seria aquele que se define pela relação ora ativa, ora passiva com a língua, que se mostra, por vezes, conhecedor do produto do conhecimento linguístico, sem, no entanto, se mostrar capaz de participar do processo de produção do conhecimento.

O QUADRO 1 apresenta um resumo geral dos tipos de enunciado e das representações indiciadas em cada tipo.

\section{QUADRO 1}

Resumo dos Grupos, dos Tipos de enunciados e das representaçōes indiciadas

\begin{tabular}{c|c|c}
\hline Tipos de enunciados & Representaçóes indiciadas & No de textos \\
\hline $\begin{array}{c}\text { Grupo 1 - Tipo 1 } \\
\text { Análise }\end{array}$ & $\begin{array}{c}\text { Professor-repassador de conteúdos } \\
\text { com alçamento a professor-investigador }\end{array}$ & 10 \\
\hline $\begin{array}{c}\text { Grupo 1 - Tipo 2 } \\
\text { Análise generalizada }\end{array}$ & Professor-repassador de conteúdos & 10 \\
\hline $\begin{array}{c}\text { Grupo 2 - Tipo 3 } \\
\text { Reformulação da narratival análise }\end{array}$ & $\begin{array}{c}\text { Professor-repassador de conteúdos } \\
\text { com alçamento a professor-investigador }\end{array}$ & 12 \\
\hline $\begin{array}{c}\text { Grupo 2 - Tipo 4 } \\
\text { Reformulação da narrativalanálise } \\
\text { generalizada }\end{array}$ & Professor-repassador de conteúdos & 18 \\
\hline $\begin{array}{c}\text { Grupo 2 - Tipo 5 } \\
\text { Reformulação da narrativa }\end{array}$ & Professor-repassador de conteúdos & 25 \\
\hline \multicolumn{2}{c}{ Total de enunciados } & 75 \\
\hline
\end{tabular}

O QUADRO 1 permite visualizar que a maior concentração das representações está relacionada ao papel de professor-repassador de conteúdos, que aparece em todos os tipos de enunciados (Tipos 1, 2, 3, 4 e 5), seja como representação isolada, seja como representação mesclada com a de professorinvestigador. 
Em 22 enunciados (Grupo 1 - Tipo 1 e Grupo 2 - Tipo 3), o que corresponde a $29 \%$ do total, houve indícios de representação do papel de professor-repassador de conteúdos com alçamento à posiçāo de professorinvestigador. Verificou-se, na interpretação desses indícios de representação, que os formandos procuraram demonstrar seus conhecimentos por meio de reflexão sobre a linguagem. Tal fato evidenciou que apreenderam: a) o conteúdo temático do enunciado da instituição, já que procuraram centrar suas respostas nos aspectos de coesão do texto-base; e b) o campo e o gênero em que se dava a interlocução, pois procuraram demonstrar sua reflexão segundo as coerções do gênero prova acadêmica.

Apesar de aparecerem indícios dessa apreensão, no entanto, os 22 enunciados agrupados no Tipo 1 e no Tipo 3 demonstraram grande instabilidade no domínio de conceitos linguísticos e no domínio das formas composicionais do gênero em que se realizava a situação comunicativa.

Assim, a tentativa de demonstração de reflexão fundamentada nos aportes linguísticos, por parte dos acadêmicos, não foi garantia de que o estilo de seus enunciados se configurasse em acordo com as expectativas genéricas. A expressividade, por vezes saliente, revelou que houve dificuldade de se manter um equilíbrio entre as coerções genéricas e as escolhas linguísticodiscursivas do enunciador. Na totalidade do fazer, revelaram um estilo ao revés do pretendido. Em outros termos, em vez de assumirem uma posição descritiva e analítica dos fatos da língua, assumiram uma posição prescritiva e fortemente marcada pela visão de "erro". Se, de um lado, o alçamento para a posição daquele que "sabe fazer" e procura demonstrar que sabe "refletir sobre sua ação" revelou o alçamento a uma posição ativa diante da língua semióforo (isto é, posição que visa à compreensão do seu funcionamento nas práticas cotidianas); de outro lado, as afirmações apreciativas revelaram-se preconceituosas em relação à atividade de escrita do aluno. Isso quer dizer que, ao mesmo tempo em que $29 \%$ dos formandos se colocaram na posição daquele que se propõe a compreender e a levar seu aluno à compreensão do funcionamento do caráter simbólico nas práticas cotidianas, colocaram-se na posição daquele que impede a compreensão do funcionamento desse caráter simbólico da língua semióforo nas práticas linguísticas de seus alunos. Associamos a essa posição sujeito o indício de representação de professorrepassador de conteúdos com alçamento a professor-investigador. Essa foi a representação que mais se aproximou das expectativas da instituição avaliadora. 
Em 53 enunciados-reposta (Tipos 2, 4 e 5), o que corresponde a $71 \%$ do total das respostas, houve marcas mais frequentes e acentuadas de alçamento à posição de professor-repassador de conteúdos. Verificou-se, na interpretação desses indícios de representação, que os formandos, ao serem chamados a identificar problemas linguístico-discursivos no texto do aluno, a apresentar soluçôes e a justificá-las com apoio de noções linguísticas, omitiram-se de demonstrar a reflexão sustentada teoricamente. Eles apenas reformularam o texto-base proposto para análise, demonstrando uma ação sobre a linguagem no mesmo nível da criança.

Sobressaiu-se nessas enunciações a liberdade expressiva do enunciador, marcada pela ausência da análise centrada no objeto (análise linguísticodiscursiva do texto da criança), pela relação passiva com a língua indiciadora de uma tendência a reforçar o caráter simbólico da língua semióforo em sua dimensão homogeneizadora das diferenças linguísticas. Tal posição indicia a defesa da unidade da língua chamada padrão e a desconsideração das variedades linguísticas. Associamos a essa posição sujeito o indício de representação de alçamento à posição de professor-repassador de conteúdos.

Faz-se pertinente trazer para esta discussão o fato de, nos enunciados do Tipo 1 e do Tipo 3, a relação dos enunciadores com a língua semióforo ter se mostrado mais complexa do que nos enunciados do Tipo 2, Tipo 4 e Tipo 5 , na medida em que, aqueles, ao procurarem pautar as respostas na busca da compreensão do funcionamento da língua, não se mostraram capazes de assumir outra posição que não a de realimentar as características de homogeneidade do símbolo revelada pela recusa da expressividade e da variedade linguística do aluno, que foram combatidas em favor da unidade da língua semióforo.

Nos enunciados do Tipo 2, do Tipo 4 e do Tipo 5, a relação com a língua se pautou pela ausência de demonstração de atitude reflexiva sustentada teoricamente, evidenciando uma visão passiva diante da língua semióforo e de forte rejeição à variedade linguística da criança.

Numa interpretação geral do posicionamento dos sujeitos, diante dos interlocutores e da língua, pudemos constatar que predominou, de um lado, a visão eufórica da homogeneidade da língua semióforo, marcada por enunciados que exaltavam essa homogeneidade, bem como a visão dicotômica entre fala e escrita; e, de outro lado, seu inverso correspondente, a visão disfórica da heterogeneidade da língua semióforo, marcada por enunciados que, realimentando o símbolo, combatiam as variedades linguísticas estigmatizadas, colocando-as fora do recorte do próprio símbolo. Tanto a visão 
eufórica da homogeneidade da língua semióforo quanto a visão disfórica de sua heterogeneidade excluem uma real consideração sobre as realizações linguísticas que os alunos apresentam, as quais vale a pena descrever, para que se possa refletir sobre elas e sobre sua função nas práticas sociais.

As realizações linguísticas, constitutivamente heterogêneas, requerem também uma visão eufórica da heterogeneidade da língua, perspectiva que tomaria a língua semióforo como objeto de reflexão crítica e de busca da compreensão das diferenças culturais e linguísticas que existem em nosso país e não podem ser vistas como ameaça à identidade da nação.

Tais interpretaçôes nos levam a verificar que os dois lugares estabelecidos como constitutivos da representação do papel do professor de Língua Portuguesa - o lugar do professor conhecedor das teorias linguísticas e o lugar do professor conhecedor da didática do ensino da língua - ao mesmo tempo em que permitiram verificar as diferentes representaçôes, permitiram constatar que a tendência predominante no ensino da língua em sala de aula ainda aponta para a continuidade da exclusão, no contexto de sala de aula, das diferentes variedades linguísticas que formam o português brasileiro.

\section{Referências}

BAKHTIN, M. Marxismo e filosofia da linguagem. São Paulo: Hucitec, 1995. 196 p. BAKHTIN, M. Estética da criação verbal. São Paulo: Martins Fontes, 2003. 421 p. BAKHTIN M.; VOLOSHINOV. V. N. Marxismo e filosofia da linguagem. São Paulo: Hucitec, 1995. 196 p.

BENVENISTE, E. Problemas de Linguística geral I. Campinas: Pontes, 19951966. 387 p.

CASTORIADIS, C. A instituição imaginária da sociedade. Rio de Janeiro: Paz e Terra, 1982. $418 \mathrm{p}$.

CASTORIADIS, C. (1991) A criação histórica e a instituição da sociedade. In: Conferências em Porto Alegre/RS/Br. Porto Alegre/RS: CANDIDO, C (Org.). Disponível em: <http://caosmose.net/costoriadis>. Acesso em: fev. 2010.

CONCEIÇÃO, R. I. S. O professor de Lingua Portuguesa na visão de formandos em Letras. 2008. 299 f. Tese (Doutorado em Letras - Área de Linguística Aplicada). São Paulo: Faculdade de Filosofia, Letras e Ciências Humanas/USP, 2008a. Disponível em: <http://www.teses.usp.br/teses/disponiveis/8/8142/ tde-18122008-121448/>. Acesso em: maio 2009.

CONCEIÇÃO, R. I. S. A língua Portuguesa no Brasil: a construção de um semióforo. In: I SIMELP - I SIMPÓSIO MUNDIAL DE ESTUDOS DE 
LÍNGUA PORTUGUESA, 1, 2008. São Paulo. Anais... São Paulo: FFLCH/USP, 2008b. V. slp27, p. 1-15.

CORRÊA, M. L. G. Relaçôes intergenéricas na análise indiciária de textos escritos. Trabalhos em Lingüistica Aplicada, Campinas/IEL, v. 45(2), p. 205-224, 2006. CORRÊA, M. L. G. O modo heterogêneo de constituição da escrita. São Paulo: Martins Fontes, 2004. 338 p.

GINZBURG, C. Mitos, emblemas e sinais: morfologia e história. São Paulo: Companhia das Letras, 1998. 288 p.

HOBSBAWM, E. J. Naçôes e nacionalismos desde 1780. Rio de Janeiro: Paz e Terra, 1990. $232 \mathrm{p}$.

MARCUSCHI, L. A. Língua falada e língua escrita no português brasileiro; distinções equivocadas e aspectos descuidados. In: IBERO-AMERICAKANISCHES INSTITUT PREUSSICHER KULTUBESITZ INTERNATIONALES KOLLOQUIUM. 1998. Anais... Berlim - Alemanha, 1998 (versão preliminar). POMIAN, K. Coleção. In.: Enciclopédia Einaudi. Lisboa: Imprensa Nacional, Casa da Moeda, v. 1, p. 51-86, 1984.

UNESCO. Declaração Mundial sobre Ensino Superior no Século XXI: visão e ação. Paris: Conferência Mundial de Educação (1998). Disponível em: <http:// www.nepp-dh.ufrj.br/onu12-2.html>. Acesso em: maio de 2009. 


\section{ANEXO}

Texto-base

Questão 1. O texto abaixo foi produzido por uma menina de 10 anos

Essa história começa com uma família que vai a uma ilha passar suas férias. Quando eles chegam eles vão logo explorando a ilha e explodem uma barreira que os impediam de passar para o outro lado da ilha.

Quando eles foram dormir eles perceberam que os bezerros começaram a correr e que quando eles foram ver o que estava assustando os bezerros. Quando eles de repente, com uma patada só um caranguejo gigante os atacou. Débora que era sua esposa começou a chorar dizendo que queria ir embora.

Quando amanheceu eles foram ver como estava o barco, para ir embora e perceberam que o barco não estava lá. Os homens saíram para explorar a ilha, e no meio do caminho encontraram um caranguejo que estava no penhasco. Eles não quiseram saber e atiraram no caranguejo que caiu ribanceira abaixo. Mas o marido de Débora, desmaiou e seu irmão não tinha como ajudá-lo, por isso foi chamar ajuda. [...]

(In: Marcuschi, L. A. Anáfora indireta: o barco textual e suas âncoras, inédito, fragmento adaptado ${ }^{3}$ ).

Uma característica desse texto é a forma como a menina faz as ligações coesivas. Elabore um texto no qual você proponha alterações para o segundo parágrafo, apresentando três soluções para o problema dos elos coesivos. Justifique as alterações sugeridas com apoio de noções linguísticas.

Recebido em setembro de 2009. Aprovado em janeiro de 2010.

\footnotetext{
${ }^{3}$ A adaptação referida pela Banca corresponde a correçôes ortográficas que havia no texto original da criança.
} 